New uses for old waterways

\author{
Francesco Vallerani and Francesco Visentin
}

\title{
Introducing watery heritage
}

Surface freshwaters system management can be considered as one of the most relevant issues affecting the quality of lived spaces in the western world. Growing water pollution and consumption, along with the opposing intensity of sudden floods and long-lasting drought, are exacerbated by the remarkable spread of both the urban sprawl phenomenon and the intensification of agribusiness. This leads to irreversible loss of the main support underpinning the basic ecosystems, with special regard to the dynamic of the hydro-geological system.

The chapter explores how the digital census and recovery of waterways as cultural and environmental heritage are becoming central features in European spatial planning. The long-lasting historical interaction between the natural base and anthropic intervention has produced peculiar waterscapes that today are linear paths of high cultural value, where it is possible to identify specific and unique cultural and environmental heritage (Castonguay and Evenden 2012; Roe and Taylor 2014). In the geographical field, many scholars consider waterscapes as the result of the intellectual (cultural) and material transformation of nature, by means of which human groups define and represent the specific dynamics of their inhabited space (Scarborough 2003; Cosgrove 2008). Rivers and canals thus become chances to place water resources and hydrographic networks at the core of urban and rural landscape planning, in which environmental, cultural, social, economic and hydraulic aspects interact (Cosgrove and Petts 1990; Mauch and Zeller 2008; Coates 2013; Gandy 2014).

The chapter aims to answer the pivotal question concerning the relationships between waterways and heritage. This research promotes knowledge of one of the most relevant characteristic forms of European heritage: rivers and canals should today be considered as a whole system that is unique world- 
wide. Waterways historically favoured the expansion of urban centres and the development of trade in Europe, thus interacting with the construction of rural landscapes. Rivers and canals were corridors that enabled the spread of trade, human mobility and knowledge, and at the same time spaces of conflicts, disasters and geopolitical territorialization.

Indeed, such a cultural and historical heritage, being a crucial component of European identity, today requires much more attention for the better preservation, use and promotion of this historic network.

Matching the main goals of this book, our contribution presents water heritage as a good example of how heritage could be interpreted and positioned dynamically as a resource for spatial planning, involving a wide range of territorial stakeholders. We develop a methodology for supporting communities and partners, including academics, to engage in research which involves producing stories, where community history and storytelling are understood as research practices. The abandoned waterways and landscape can speak to the present and tell stories related to heritage through collecting rare interviews and narratives, in order to demonstrate their rich past and contrast with generic stereotypes.

This approach is perfectly suited to historic European waterways, especially when considering minor hydrographic networks. Historical waterways management actually implies innovative conservation practices; entailing not only cultural issues, but also economic interests, social needs and ecological aspects.

Minor rivers and historic canals are particularly challenging in the ongoing evolution of climate change. We are furthermore aware of the need for a new paradigm of water management to secure more sustainable water uses, through a far-sighted combination of digital technologies with innovative models of heritage planning (Opmeer and Visentin 2018). Taking into account the results achieved by the international research project 'EUWATHER' (European Waterways Heritage), this chapter will try to demonstrate how minor rivers and historic canals, as cultural corridors, allow societies to take advantage of the positive connections between cultural and environmental dimensions, between landscape and heritage and between local attitudes and global changes. Freshwater's general dwindling could be coped with through better management of inland hydrography as recovered cultural heritage, thanks to the increased demand for river tourism and leisure activities (Prideaux and Cooper 2009). 


\section{European historical waterways: towards a polyphonic geography}

After World War II, the decline of waterways transport in Europe implied also the loss of the symbolic and memorial values of old waterscapes as cultural heritage. It was only during the last decades of the twentieth century that a more mature consideration developed of the historical and cultural meaning of premodern European waterways. We are now dealing with a well-defined hydrographic heritage and current times are ready for broadening the awareness of waterways with regard to their multifunctional role, especially when considering spatial planning processes. Waterways have become places of entanglement where it is possible to enlarge the platform of local actors, thereby integrating the institutional range of heritage and tourism experts (Tang and Jang 2010; Kaaristo and Rhoden 2017).

Our account focuses on the comparative analysis of three case studies in Italy, Spain and England as interesting sample areas for evaluating the multifunctional nature of the cultural heritage detectable along the hydrographic network, to be collocated within the pan-European discussion on water management. From this point of view, tied to the complex multifunctional approach, an attempt was made to assess the functional evolution of these minor rivers and historic canals not only as elements contributing to the equilibrium of the area, both ecological and hydraulic, but also as cultural corridors to be recovered.

\section{Italy: minor rivers and canals in the Venice inland}

In Italy, we looked at the hinterland of Venice, in particular inland territory crossed by the low course of the Bacchiglione and Sile rivers, roughly extending from Padua and Treviso towards the Venice lagoon. This specific hydrographic context, started in the Middle Ages and developing since the mid-fifteenth century, represents an important example of fruitful construction of one of the most productive agrarian landscapes in Europe (Ciriacono 2006). This complex rural landscape, crossed by a waterways network, gave life to what has been recognized as a 'Palladian Landscape' (Cosgrove 1993).

Similar transformations have required specialized knowledge to deal with natural landforms and hydro-morphology, while accommodating specific cultural approaches and socioeconomic contexts. Yet, despite the high level of sophistication of its historic water-landscape, the rich heritage of the Venetian waterways along the inland canal system is today largely forgotten. After the 
fall of the Venetian Republic (1797), up to the mid-twentieth century, the hydrographic system managed to maintain a fair balance between agricultural functions and hydraulic energy and the environmental quality of a suggestive rural landscape. Modernity produced changes, which have continued up to the present day, as in the case of hydro-geological risk or the extensive pollution of surface waters and groundwater caused both by industry and by the fertilizers used in agriculture. The concrete loss of ecological and cultural heritage caused by the frequent burying of entire drainage systems, due to uncontrolled urban and agricultural development along river banks, has also reduced people's tangible and intangible recognition or appreciation of waterscapes and related heritage. The result is the obliteration of the waterways heritage to the extent that today it is in a state of abandonment and disrepair, causing ecological and even water management problems.

\section{Spain: the historic canals of Bajo Ampurdàn - multifunctionality or abandonment?}

In its final stretch, the river Ter flows over a plain called Bajo Ampurdàn (Province of Girona, Catalonia). In this area, the first attempts to regulate the river date back to Roman (first and second centuries) and Arab times (seventh and eighth centuries). Despite these early efforts, up to the modern age the area has always been considered swampy, above all due to the frequent overflowing of the river Ter. Between the twelfth and fourteenth centuries, small drainage canals, barriers and dykes were built to drain the water and make the plain fertile and inhabitable (Soldevila 2007). Between the sixteenth and seventeenth centuries, a number of canals were upgraded and strengthened. The complex system of hydraulic infrastructures was designed and implemented not only to drain and control the waters which invade this plain, but also to irrigate fields and vegetable gardens and drive numerous mills.

Ever since they were built, right up to the present, these canals have also played a crucial role from the environmental point of view. These blue and green lines are a favourable habitat for many kinds of animals and plants. They also act as ecological corridors and, finally, affect the regulation of the water table and floodwaters. The routes of the two canals should not be underestimated: they cross a number of historic boroughs, giving them an original character and determining particular types of settlements and architectures (Ribas et al. 2012; Llausàs et al. 2020). This delicate watery heritage is at risk due to a number of modernization projects proposed by the Comunitat de Regants (Canal management and maintenance bodies) for the purpose of cutting both the consumption of water for irrigation and routine maintenance costs. These projects were opposed by a number of environmental groups, but also by 
important sectors of the Comunitat de Regantes and local communities. The doubts concern not only economic aspects, in view of the high costs involved - around $€ 30$ million - but also the concrete risk of abandoning historical courses, a reduction in ecological functionality and the hydro-geological state of the area (Pavon et al. 2014).

\section{England: from canal mania to restoring mania}

The extensive network of English canals is interlinked with an equally complex natural hydrographic pattern with constant water flows. Along with the consolidation of political and commercial power in England during the seventeenth century, the hydraulic issue became a strategic one for land development. The building of the Rochdale and Ashton Canal in Greater Manchester between 1794 and 1804 was one of the most daring engineering works of the age and one that embodies and kindles the panorama of the modernist dream to transform the natural environment (Clew 1985). This historical period has been defined by many scholars as the 'Canal Age' or 'Canal Mania', underlining a widespread interest in the construction of inland waterways to link seaports with the thriving manufacturing and mining districts of the hinterland (Hadfield 1969). This network fell largely into dereliction after the introduction of railways.

The redundancy of these hydraulic works risked jeopardizing the heritage value of landscape characteristics essential in defining the nature of English rurality and urban waterfronts. And, in fact, after World War II, thanks to the efforts of the Inland Waterways Association (IWA) with the aid of numerous local volunteers who formed groups to restore individual canal sections, a slow but growing interest began in artificial waterways, reinventing this landscape as a space mostly for leisure and tourism. The role of these associations was essential in initiating extensive restoration works funded by the government and coordinated by the government body British Waterways (BW).

Today, the majority of the waterways are managed by the Canal and River Trust (which has replaced the BW), which promotes their use by the 65.5 million population of the UK, nearly half of whom live within $8 \mathrm{~km}$ of a waterway - where one can find five World Heritage Sites, 47 scheduled monuments and the third-largest collection of listed buildings in the country (Canal and River Trust 2016). Apart from these figures, the social, environmental, economic and landscape value of waterways has enabled the English countryside to maintain the imaginary image of traditional rurality, and has also developed numerous new activities, especially related to leisure boating, angling, walking 
and cycling, able to give back meaning to places and restore ecological quality along the hydrographic network (Monahan and Spencer 2004).

\section{Minor waterways as cultural corridors}

From the case-study analysis, it becomes evident that there is a growing interest in waterscapes among the public in general, consistent with more general topics tied to current discussions on the new socioeconomic structures of the post-industrial age. The suggestive intertwining of waterways, most of which are marginal with respect to the urban expansion subsequent to the prevalence of roadways, represents a major environmental heritage, where the interaction between natural base and anthropic intervention has produced significant landscape types. Effective in this respect is the definition of waterways as 'cultural corridors', thanks above all not only to the presence of constructions related to specific hydraulic functions, but also of stately homes, places of worship, country homes and proto-industrial activity buildings.

This is besides an environmental system with a keen vocation for cultural tourism, involving not only leisure boating but also special trips along the rivers (Erfurt-Cooper 2009). The recovery of post-industrial structures is deemed a good strategy to achieve profitable environmental planning. It follows that artificial waterways represent, in all regional contexts, a concrete challenge for developing policies aimed at increasing biodiversity, managing freshwater supply and balancing negative effects of urban sprawl.

A range of topics from modernity to citizenship, once largely inland matters, are now on the waterfront, materially and imaginatively (Daniels 2018). Certain social developments contribute to this new aquatic scholarly sensibility, especially when considering the problems of water supply and floods in expanding urban areas, and the rediscovery and gentrification of formerly working waterfronts, from docklands to canals, in most of the global post-industrial cities. Rising sea levels, associated with global warming, seep into the urban imagination. Minor rivers and small canals offer a great opportunity to analyse and develop new studies and approaches in specific contexts (Vallerani and Visentin 2018). Our attention paid to minor hydrographic networks could be retained as an interpretative model to fill the gap between cultural heritage and environmental issues, with special regard to water runoff management and blue-ways regeneration. The project investigated how citizens' perceptions have been developing a shared awareness about waterways. The information coming from our research - the workshops, the personal 
meetings with local experts and historians, the surveys and the field work must be understood as an innovative attempt to evaluate the increasing role of bottom-up competencies.

The EUWATHER conceptual framework for this research is known as the Collaborative Stories Spiral (CSS). It is a new approach to the generation and use of oral histories (Gilchrist et al. 2015). Building upon conventional participatory approaches to research, CSS offers a framework within which oral histories are simultaneously generated, mediated and remediated as a means of co-creating a deep cultural understanding of Europe's smaller waterways. Through the CSS, it is possible to recognize that minor hydrography offers not only valuable assets that are at the core of landscape management, but also the preservation of a hidden local culture patrimony.

Such hydraulic heritage has to be furthermore considered for its intangible aspects that could matter deeply to people, involving both 'familiarity' and the complex emotional (and often unknown) relationships that affect what is understood as 'sense of place' (Vallerani 2018, 9-11). The whole of Europe is an endless repository of water-related stories simply waiting to be re-told, re-evaluated, surveyed and catalogued, to deal with the silent and hidden impoverishment of a significant aspect of our continent's cultural heritage (Ricoeur 1984). Oral history has thereby been taken into account, according to the increasing relevance of the 'telling turn' (Lorimer and Parr 2014). This specific point of view has allowed us to stress the 'productive' and 'living' disposition of small stories and how these stories could stimulate the development of a sort of hydraulic humanism, which should underpin the recovery and reorganization of European hydro-geological management.

One of the final project outputs was to develop new opportunities for ecotourism and outdoor recreation as a driver for sustainable development. For this purpose, a number of digital itineraries have been co-designed with local communities, commercial stakeholders and the public sector as a way for outdoor public mobilization and education. We have sought to understand the impact of free-choice learning experiences on tourists' understanding and appreciation of minor water heritage sites. From the first empirical tests, the results indicate that learning is a cumulative process that not only occurs onsite, but also is highly influenced by pre-visit assets and post-visit experiences (Ballantyne and Packer 2011; Opmeer and Visentin 2018, 128). 


\section{Further research trajectories}

Much has been written about the multiple values of the major waterways of Europe. The network of secondary or 'minor' regional hydrography - minor rivers and historic canals, for example - is equally significant in forming a multifunctional resource that can address the objectives of both the Water Framework Directive 2000/60 and the new European agenda as set out in Europe 2020. The idea of multifunctionality is consistent with a holistic understanding of the culture-nature relationship, going well beyond the framework of customary heritage conservation found in traditional cultural landscape studies. Nowadays, the evolutionary process affecting global environmental quality is really relevant; therefore, surface freshwater system management can be considered one of the most strategic issues in an effectual interaction with the recovery of awareness of ordinary landscapes.

Water management activities have also come under increased scrutiny, not only because they refer to physical elements of natural systems, but because they are strategic for people's quality of life. As underlined by the Water Framework Directive 2000/60 in the incipit (DIRECTIVE 2000/60/EC: 1), the relationship between water resources and people's lives needs new policies that take into account the local expertise to achieve better hydrography management. Improving the involvement of riverine communities in decision-making is crucial to transmit to future generations a truly supported, holistic approach to water rather than just false nostalgia for premodern singular and coherent places as a palliative in a technocratic approach led by faith in physical transformations of waterscapes.

In geographical studies related to tourism, the presence or absence of river tourism activities along a waterway can tell us what kinds of relationships a society has with the hydrographic networks of its territory and what kinds of cultural dialogues spring from it. This discourse is not only about tourism per se, but also about how waterscapes are responding to political and economic changes at all levels. Thus, no studies of changes to rivers and canals should overlook tourism, and efforts must be made to examine how tourism fits into broader questions of sustainable growth and development related to waterscapes. One of the aims was to join the research interests (on tourism and analysis of the cultural water heritage) with some of the potential key factors for the development of local awareness in order to create renewed visions and a new imaginary about inland water in order to avoid disconnecting imagination of the landscape from its natural environment. 
The research is thereby devoted to the users of inland waterways, exposing the importance of a new accessibility to heritage through digitalization. This approach should improve people's understandings of waterways, fostering policies to maintain their character of a common good. The socioeconomic potential of the cultural heritage along minor river corridors and historic canals could furthermore be used to improve regional and economic development in terms of increases in tourism and local leisure activities. It follows that the social benefits arising from renewed multiple functionalities of minor hydrography networks could be enhanced in the process of regeneration of neglected or abandoned waterscapes (Visentin 2019).

In order to further substantiate these findings, the research group aims to go ahead in investigating in depth the socio-spatial relations activated by water elements in the past to be able to analyse the present-day relationship between members of society and their landscapes (Pitt 2018; Pitt 2019). Therefore, this research is strongly related to more innovative conservation practices, including profitable interactions with landscape design, urban planning and tourism economics. The landscape of water - the hydro-landscape - is not the mere result of human activity: it is both a material thing and a conceptual framing of the world. It follows that the key concept of our contribution cannot only be the 'recovery of waterfront' according to the commonly accepted definition, affecting relevant sections of cultural landscapes where the post-industrial option is now increasingly an attractive starting point for interaction between global processes and local perspectives. Rather, it is a unique setting where old infrastructures and abandoned artefacts may greatly inspire collective imagination.

Thus, it is almost a vital necessity to be aware of the growing social demand for blue spaces and attractive landscapes like waterways and small river corridors. Finally, such a revalorization process of water landscapes plays a relevant role not only in urbanized areas but also in the sectors of the lower plains (like in the Spanish and Italian case studies we are dealing with) that were transformed in the past by large drainage projects to make the land suitable for agribusiness.

\section{References}

Ballantyne, R. and J. Packer (2011), 'Using tourism freechoice learning experiences to promote environmentally sustainable behaviour: the role of post-visit "action resources"', Environmental Education Research, 17 (2), 201-15. 
Canal and River Trust (2016), Our canal \& River Network, accessed 11 December 2018 at https://canalrivertrust.org.uk/enjoy-the-waterways/canal-and-river-network

Castonguay, S. and M. Evenden (eds) (2012), Urban Rivers. Remaking Rivers, Cities and Space in Europe and North America, Pittsburgh, PA: University of Pittsburgh Press.

Ciriacono, S. (2006), Building on Water: Venice, Holland, and the Construction of the European Landscape in Early Modern Times, Oxford: Berghahn Books.

Clew, K.R. (1985), The Kennet \& Avon Canal, Newton Abbot: David \& Charles.

Coates, P. (2013), A Story of Six Rivers. History, Culture and Ecology, London: Reaktion.

Cosgrove, D. (1993), The Palladian Landscape: Geographical Change and Its Cultural Representations in Sixteenth Century Italy, Philadelphia, PA: Pennsylvania State University Press.

Cosgrove, D. (2008), Geography and Vision: Seeing, Imagining and Representing the World, London and New York: Tauris.

Cosgrove, D. and G. Petts (eds) (1990), Water Engineering and Landscape, London and New York: Belhaven Press.

Daniels, S. (2018), 'Towards homogeneous waterfronts? Historical woodworking waterfronts in transition', in F. Vallerani and F. Visentin (eds), Waterways and the Cultural Landscape, London and New York: Routledge, 19-28.

Erfurt-Cooper, P. (2009), 'European waterways as a source of leisure and recreation', in B. Prideaux and M. Cooper (eds), River Tourism, Wallingford, UK: CABI Publishing, 95-116.

Gandy, M. (2014), The Fabric of Space. Water, Modernity and Urban Imagination, Cambridge, MA: MIT Press.

Gilchrist, P., C. Holmes, A. Lee, N. Moore and N. Ravenscroft (2015), 'Co-designing non-hierarchical community arts research: the collaborative stories spiral', Qualitative Research Journal, 15 (4), 459-71.

Hadfield, C. (1969), The Canal Age, Newton Abbot: David \& Charles.

Kaaristo, M. and S. Rhoden (2017), 'Everyday life and water tourism mobilities: mundane aspects of canal travel', Tourism Geographies, 19 (1), 78-95.

Llausàs, A., A. Ribas, S. Ricart and D. Roset (2020), 'What future for decommissioned historic irrigation canals? Crafting new identities in the Lower Ter (Spain)', Landscape Research, 45 (5), 601-14.

Lorimer, H. and H. Parr (2014) 'Excursion - telling stories and journeys', Cultural Geographies, 21 (4), 543-7.

Mauch, C. and T. Zeller (eds) (2008), Rivers in History: Perspectives on Waterways in Europe and North America, Pittsburgh, PA: University of Pittsburgh Press.

Monahan, D. and C. Spencer (2004), 'From trade to tourism: the Rochdale Canal, 1794-2004', Transactions of the Halifax Antiquarian Society, 12, 31-47.

Opmeer, M. and F. Visentin (2018), 'Geo-based technology in support of creating a seamless free-choice learning experience on minor water-heritage sites. Lessons learned from the EUWATHER project', in V. Albanese, V. Greco and M. Proto (eds), Geography and the ICT. New Technologies \& Geographical Research, Bologna: Bononia University Press, 113-32.

Pavon, D., F. Visentin, A. Ribas and F. Vallerani (2014), 'Multifuncionalidad y retos de futuro en el paisaje cultural del regadio del Bajo Ter', in C. Sanchis-Ibor, G. Palau-Salvador, I. Mangue-Alferez, and L.P. Martinez-Sanmatín (eds), Irrigation, Society and Landscape. Tribute to Thomas Glick, Valencia: Editorìal Politècnica, 720-37.

Pitt, H. (2018), 'Muddying the waters: what urban waterways reveal about bluespaces and wellbeing', Geoforum, 92, 161-70. 
Pitt, H. (2019), 'What prevents people accessing urban bluespaces? A qualitative study', Urban Forestry \& Urban Greening, 39, 89-97.

Prideaux, B. and M. Cooper (eds) (2009), River Tourism, Wallingford, UK: CABI Publishing.

Ribas, A., A. Llausàs, D. Saurí and D. Roset (2012), 'El paper dels recs de Sentmenat i del Molí de Pals en la configuració de la plana agrí cola del Baix Ter', Estudis d'Història Agrària, 23, 319-34.

Ricoeur, P. (1984), Time and Narrative, vol. 1, Chicago, IL: University of Chicago Press.

Roe, M. and K. Taylor (eds) (2014), New Cultural Landscapes, London and New York: Routledge.

Scarborough, V. (2003), The Flow of Power: Ancient Water Systems and Landscapes, Santa Fe: School of American Research.

Soldevila, X. (2007) 'Entre les aigües i el bosc. Impression del paisatge medieval a la plana del Baix Ter (segles XII-XIV)', in Actes del Congrés: El Paisatge, element vertebrador de la identitat empordanesa, vol. II, Figueres: Institut d'Estudis Empordanesos, 345-53.

Tang, L. and S. Jang (2010), 'The evolution from transportation to tourism: the case of the New York canal system', Tourism Geographies, 12 (3), 435-59.

Vallerani, F. (2018), 'Introduction. Flowing consciousness and the becoming of waterscapes', in F. Vallerani and F. Visentin (eds), Waterways and the Cultural Landscape, London and New York: Routledge, 1-16.

Vallerani, F. and F. Visentin (eds) (2018), Waterways and the Cultural Landscape, London and New York: Routledge.

Visentin, F. (2019), 'Idro-geografie e senso del luogo: dalle memorie al ruolo delle comunità locali', Semestrale di Studi e Ricerche di Geografia, XXXI (1), 119-35. 
Francesco Vallerani and Francesco Visentin - 9781788974639 Downloaded from PubFactory at 04/26/2023 12:04:07PM 